\title{
Evaluation of the Effect of Physically Magnetized Water on Some Properties of Dental Stone
}

Ahmed I. Jasim Al-Khyeat BDS, MSc (Assist Lect.)
Department of Prosthodontic

College of Dentistry, University of Mosul

\begin{abstract}
الخلاصة

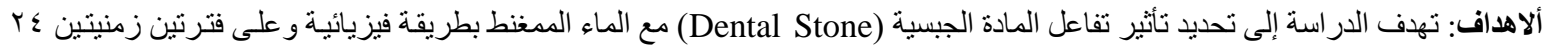

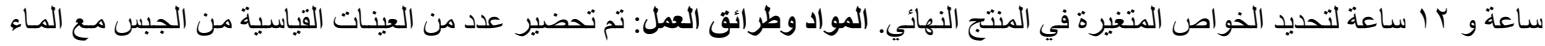

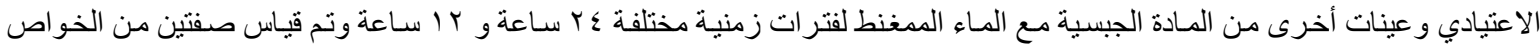

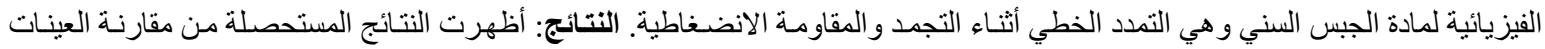

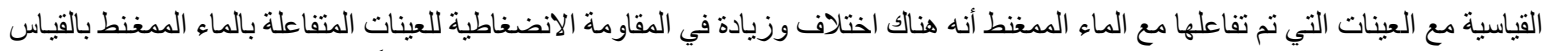

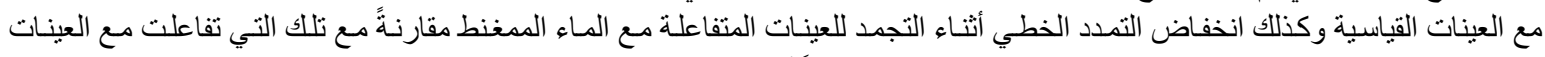

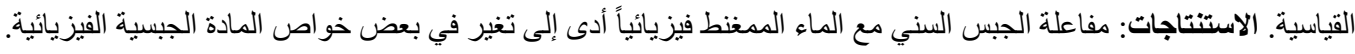

\begin{abstract}
Aims: to study the effect of interaction of dental stone with tap water and physically magnetized water on two periods of time $24 \mathrm{~h}$. and $12 \mathrm{~h}$ to study the change in the physical properties of final product. Materials and Methods: We started prepair no. of control samples and other of samples interacted with physically magnetized water for two periods of time $24 \mathrm{~h}$ and $12 \mathrm{~h}$, then we studied the liner setting expansion and compressive strength.. Results: results obtained from comparing control sample with that treated with physically magnetized water showed an increase in the compressive strength of physically magnetized group and decrease of linear setting expansion in comparison with that of control sample. Conclusion: Reaction of dental stone with physically magnetized water lead to change in some physical properties of dental stone.
\end{abstract}

Key words: Magnetized water, liner setting expansion, compressive strength, dental stone

. Evaluation of the Effect of Physically Magnetized Water on Some Properties of Dental Stone. AlRafidain Dent J. 2019;19(1):32-41.

Received: 2/ 5/ 2019

Sent to Referees: 5/5/2019

Accepted for Publication: 4/ 7/ 2019

\section{INTRODUCTION}

Magnetic field (MF) is generated by the movement of the electrons, weather activated by electric cument or via nature source magnetism, unlike the electrical field, magnetic field aren't reduced by objects, the field passes easily through different barriers. The strength of magnetic field is measured in (tesla), although we generally use a much smaller unit such as the microtesla (uT). ${ }^{(1,2)}$ It is well known that the effect of (MF) on water becomes a complex and multiracial character that in final result affects the structure of water and hydrated ions, as well as the physicochemical properties behavior of inorganic salts, so when (MF) applied to water ${ }^{(3)}$, it will alter the chemical reactions via competing between dissolution and precipitation resulting in the colloidal complexes and improves electrocoagulation follow by sedimentation and 
crystallization of scaling salts of $\mathrm{Ca}^{2+}, \mathrm{Mg}^{2+}$, $\mathrm{Fe}^{2+}$ and $\mathrm{Fe}^{3+(4)}$. (MF) interaction with water is based on the influence (MF) on the treated water which lead to spontaneous formation and decay of colloidal complexes of metal and $\mathrm{Ca}^{2+}, \mathrm{Mg}^{2+}, \mathrm{Fe}^{2+}$ Fragments of decay further form the citrates of nucleation of inorganic salts accelerating subsequent sedimentation and a microinculation of few magnetic iron particles of $\mathrm{Fe}_{2} \mathrm{O}_{3}$ in water intensifies the formation of colloidal hydrophobic sols of $\mathrm{Fe}^{3+}$ cautions with chlorine ${ }^{(5)}$, another hypothesis postulated that the magnetic field due to dipole polarization of water molecule directly influences the structure of water with the formation of verity of $\mathrm{H}_{2} \mathrm{O}$ molecule bonded to each other via low energy intermolecular (vanderwaals forces) which may cause deformation of hydrogen bonds and partial rupture alter structure of water that leads to the change in density, viscosity, $\mathrm{PH}$ value, physical and chemical process like dissolution and crystallization of inorganic salts ${ }^{(6,7)}$. Scalar energy discovery attributed to the jams clerk Maxwell, and it is non-linear, non-hertzian field-like circles, fills environment, stationary from of energy ${ }^{(8)}$, ((energy that develop and formed by two similar frequencies coming from opposite directions meet, they cancel each other out, and the energy result usually calld stationary ${ }^{(9,10)}$. Scalar energy acts to physically magnetized water by lowering the surface tension than regular water. So, this will lead to affect physical properties and weakened the intraclusters hydrogen bonds, breaking larg clusers ${ }^{(12,11)}$. Once the water molecular is been subjectual to the scalar engery, it will become fully magnetized, and since pola liquid with two charge (+ve and -ve), the water molecular because magnetically active affecting and affected by field around it, although the change over water molecular is neutral, but its not uniform over entire it. This mean the water is with two charge at each end so the water molecude will group together in from of "cluster" ${ }^{(13,14)}$. When these "cluster" of water groping together in smaller groping, this will lead to increase the bio-availability of the water and make it more easily able to pass and transport and if we assumed that all dental stone used in dental depend on how much water presense in the cast materials, so when we treat dental stone with scalar energized water, find crystal formed will disappears faster after interact with dental stone partical and will react with it at high level than happen usually with changes in physical properties of dental stone ${ }^{(15)}$. The compressive strength is usually used to test the strength of the specimen of ordinary water make and that of physical magnetized water scalar energylized water and its value was determined according to ADA specification No $25(1975)^{(16)}$.To be clinically useful, dental stone material should possess high compressive strength and highly resistance to deformity, since the compressive strength is mainly related to water - powder ratio, mixing time, volume mixture, humidity, this will play 
significant role in providing a product with superior physical properties for dental application $^{(17)}$.

\section{MATERIALS AND METHODS}

This study was conducted in an environmental with temperature of $\left(20-25^{\circ} \mathrm{C}\right)$ with $\left( \pm 2{ }^{\circ} \mathrm{C}\right)$ and relative humidity of $50 \%( \pm 10 \%)$, according to the American dental association specification (A.D.A) No. 25. The material used were had casted dental stone (synaRock), Scalar energized water device for physically magnetized water with scalar energy as in Figure. (1)

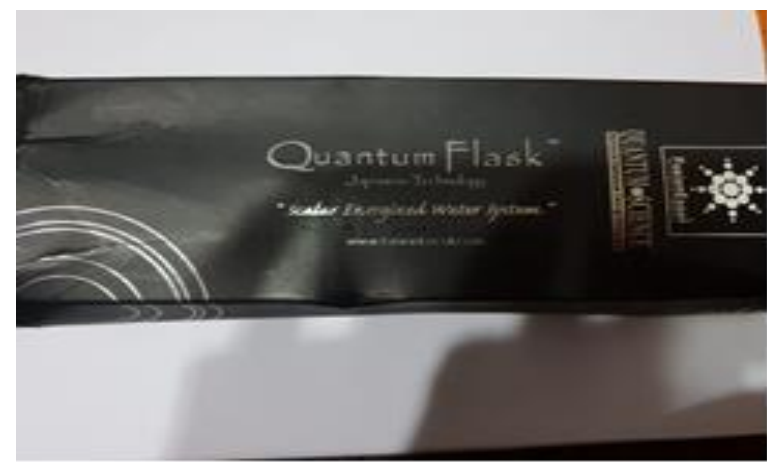

Figure (1): device of scalar physically magnetized water

(Quantum flask/ Japanese Technology) metal mould for pouring sample of compressive strength, separating medium, graduated cylinder, spatula, rubber bowel bond, digital scalar for weighly exact ratio of powder-water to mix, devices measure compressive strength and of modified linear setting expansion. For Compressive Strength. A special split metal mold were used to prepair "6" cylindrical specimen of $20 \mathrm{~mm}$ in diameter and $40 \mathrm{mn}$ in length, then $100 \mathrm{gm}$ of dental stone were mixed with "20"mm of water according to manufacture instruction, the mold cover with separating medium to facilitate removal of sample after being set, the prepare mixture was poured side of the side of the mould retain on glass plate, then, it will vibrate gently while being filled, the over filled mould covered with second plate-glass while rocked into place and passed firmly into contact with top surface of the mould to ensure parallel end, specimen remolded from split mold after 30min from start point of mixing, the sample was crushed by using compressive machine with load rate of about $2900 \pm / 90 \mathrm{~N} / \mathrm{mm}^{2}\left(300 \pm 50 \mathrm{~kg} / \mathrm{cm}^{2}\right)$ for dental stone and then it will tested on universal compressive strength (20).

\section{Linear Setting Expansion Measurement.}

The device used for measurement of Linear Setting Expansion expasive consist of rectangular metal box having dimension of 104 
$\mathrm{mm}$ in length and $58 \mathrm{~mm}$ in width with one fixed end stop and one moveable brass slide, the motion of the free brass end was monitored by a dial gage against the brass slide movement as in the dial gage adjust on by place pointer on zero. change in specimen length mean by difference in initial rend (IR) and final read (FR).

\section{Samples Testing:}

This study was conducted on 3 groups as follows:

- Group 1: Control dental stone is prepared according to manufacture is instruction.

- Group 2: Replacement of ordinary water with physically- (scalar) magnetized water for $24 \mathrm{~h}$ complete.

- Group 3: Replacement ordinary water with physically - (scalar) magnetized water for $12 \mathrm{~h}$ complete.

All the sample were prepared according to manufacture instruction, for control sample,

\section{RESULTS}

The data of mean and standard deviation with no. of samples with Duncan sign for two experts with $12 \mathrm{~h}$. and $24 \mathrm{~h}$ scalar energy cycle with "p" value ray acceding to Duncoy Multi test done. one hundred gram of dental stone (by weight) with $20 \mathrm{ml}$ of tap ordinary water for control sample, and with $20 \mathrm{ml}$ of physical magnetized water on two period $24 \mathrm{~h}$, and $12 \mathrm{~h}$.

For the compressive strength, the value the test was determined for the value of the maximum load at the point of specima fracture according to formula:

$\left(\right.$ compressive strength $\left.=\frac{\text { Load }(\mathrm{kg})}{\operatorname{Area}\left(\mathrm{cm}^{2}\right) * \chi}\right)$

Where $\boldsymbol{X}=$ surface aver of circle $=3.14^{2}(21)$

And for linear setting expansion the difference between the initial reading (IR) of setting time and final reading (FR) after two hours was taken, the value of expansion was calculate according to formula:

$\Delta \mathrm{L} \%=\mathrm{FR}-\mathrm{IR} / \mathrm{L} \times 100$

where $\Delta \mathrm{L} \%=$ percentage of setting expansion $\mathrm{L}=$ actual leg of length specimen (20,22)

The analysis of variance (AVOVA) for two experts has shown a significant value of "P" as shown in table (1), with high value of expert 1 that it's value for expert 2 . 
Table (1): Analysis of variance (ANOVA)

\begin{tabular}{ccccccc}
\hline & S.O.V & df & SS & MS & F value & P value \\
\cline { 2 - 7 } Exper1 & Between group & 2 & 304.053 & 152.026 & \multirow{2}{*}{2088.92} & \multirow{2}{*}{$0.001 * *$} \\
& Within group & 15 & 1.091 & 0.072 & & \\
\cline { 2 - 7 } Exper2 & Total & 17 & 305.145 & & \multirow{2}{*}{$001 * *$} \\
& Between group & 2 & 102.49 & 51.246 & \\
& Within group & 15 & 8.286 & 0.552 & & \\
\hline
\end{tabular}

** Significant difference exited at $\mathrm{P}<0.01$

Histogram for compressive strength has shown a high and best value for (24h) stimulation as shown in Figure (2).

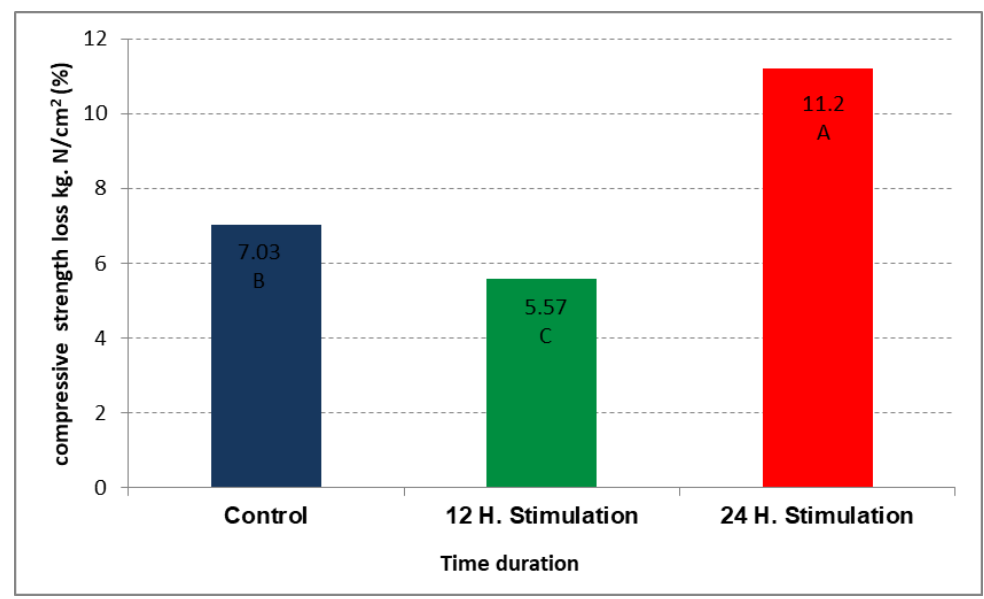

Figure (2): Degradation and percentage chances in the compressive strength of Dental stone specimens for $12 \mathrm{H}, 24 \mathrm{H}$ stimulation compare with that of control samples.

Compare with results of $12 \mathrm{H}$ stimulation which show a low value than that of control un stimulated samples and with same time duration for experiment. With highly significant $\mathrm{P}$ value compare with that for control un stimulated samples and for that of $12 \mathrm{H}$ value. Histogram for linear setting expansion has shown low and best value for control. stimulation compare with $12 \mathrm{H}-24 \mathrm{H}$, stimulation with value of $\mathrm{P}$ less significant for stimulated groups $12 \mathrm{H}$ and $24 \mathrm{H}$, and the higher value for control gur. As shown in Figure (3). 


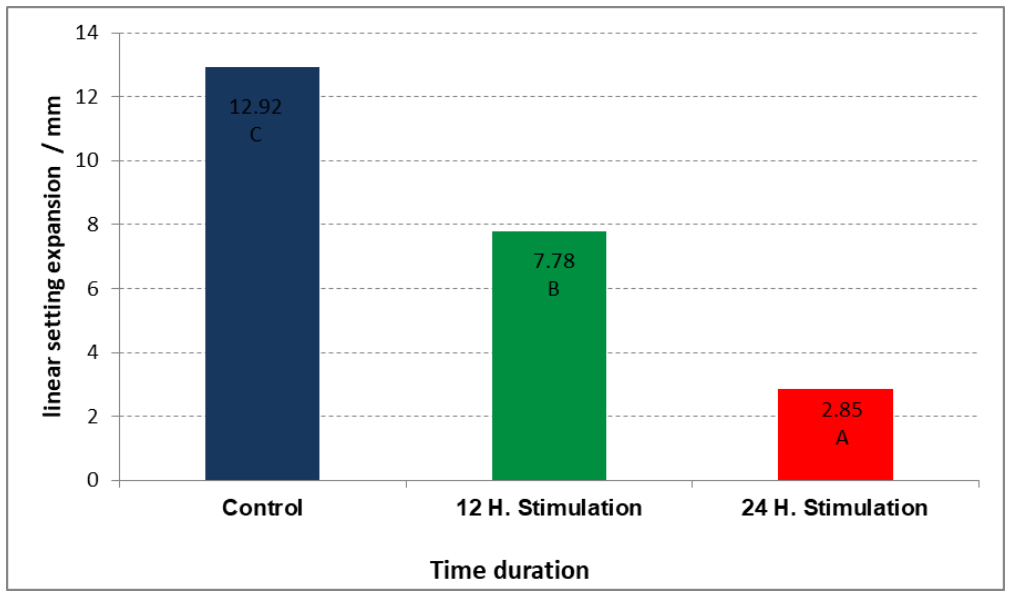

Figure (3): Percentage of chances in the linear setting expansion Dental stone specimens for $12 \mathrm{H}$, $14 \mathrm{H}$ stimulation compare with that of control samples

\section{DISCUSSION}

In our study we compare in between one control group and two others group of $24 \mathrm{~h}$, and $12 \mathrm{~h}$ magnetized water with scalar device. For the compressive strength our experiment has shown that compressive strength for dental stone treated with physically magnetized water has shown an increase in the value of compressive strength of 24 hours period, and to a less degree increase In the compressive strength of $12 \mathrm{~h}$, compare with that control group this result can agree with finding (Wang Y. et al) how found that magnetic field could enhance the physicochemical prosperities of water and could enhanced conductivity (23). And the water power ratio of dental stone was been Affected by (MF) and changes in crystal shape and form but only when cycle completed for $12 \mathrm{H}$ and not for $12 \mathrm{H}$. Also, the result of $12 \mathrm{~h}$ and $24 \mathrm{~h}$ could be agree with (Ghorbanis et al) how found that scalar energized water is with different mechanical electrodynamics and thermodynamic properties compare to regular water, so molecule energy will be reach to maximum rate with 24hours energized water, and this activity of water molecule weakened when not complete it is magnetized cycle and this explain result of $12 \mathrm{~h}$ duration, which shown an effect but not strong as that $24 \mathrm{~h}(24)$. Result's also agree with finding of (Esmaeil nezheel E., et al), as they use magnetized (Scalar energized) water can improve flow ability and viscosity of water and lower the surface tension of water which lead to high activity dental stone partials with variable 
adhesine interactiy facet leod to better improvement in final products. Result showed for linear setting expensive can agree with that (Orlov and Andrianov) as the setting expansion of water magnetized energy lower than of regular tab water and this due to role of magnetized water to remove some of supersaturating water as for sold or gaseous phase allowing to the smallest particles having sharp corners to form seed crystals which can be contributed to bulk crystallization of particles since the setting expansion of cluster stone is basically based one calcium sulphate hydration during mix which promotes the reaction where crystal growth occur up to 0.5-0.6, while with magnetized water we decrease expansion up to $0.1 \%$ by enhanced the physical properties and thus allow to faster vaporization of water than regular lead to low setting expansion, So keeping chemical composition of dental stone with balanced mixture to maintain it's specification Accepted According to (ADA).

\section{CONCLUSIONS}

This study has examined the effect of physically magnetized water with scalar energy placed inside device for two period of $24 \mathrm{~h}$ and $12 \mathrm{~h}$, on physical properties of dental stones (MF) has change some of these properties like surface tension, conductivity, flow ability lead to dental stone with high compressive strength and with low setting expansion compare that of ordinal tab water. The rate of increase varies for different mixes and the result obtain remain with accepted (ADA) specification. The expected improvement grew as the number of times that water passed through the permanent magnetic fields is increased, and reducing linear expansion.

\section{REFERENCES}

1. T. yang, Xiao. C, Liu,. J. Water Research: aiar. J. international Academic, 2017 (41): 20 45954610.

2. Chibowski. E. , Szczesl, Hoysz.,. Effect of a static magnetic field on water and electolyte solution: J colloid interface Sci, 2017 (316); 996.

3. Wang Y., Wei H., Luo J.. Influence of magnetic water on early-age shrinkage craking of concrete., J constv. Build matev; 2017 (147): 91-100. 
4. Mosin O. V;. Prospects and directions of magnetic water treatment; J. Energosber. i. rodopodg: (5); 2011, 29-32 (Russian).

5. Dziar. J Toledo J., Ramalho. K.: Effect of an external magnetic field on physical- chemical prosperities: J. Md; struct. 2016.

6. KotB A., Aziz A.M.. Scientific investigations on the claims of the magnetic water condition; international Journal of Enger; (4): 2013, ISSN 1584-1637.

7. Maffei ME.. Magnetic field effects on plant growth, development, and evaluation, J. Plant sci.; (1) 5, 2017: 1-15.

8. Khurshid Z.; Sheick Z., Zafar M: Dental materials principles and application: J. Paramount: (4): 2018, 1-2.

9. Cesero De., Mote EG., Spohr AM:. The influence of post pouring time on the roughness, compressive strength, and diametric tensile study of dental stone, J. prosthet. Dent (112); 2014, 1575-1577.
10. Silva M., Consani S., Sinhorti M., mesquite M.: Linear dimension change, compressive strength and detail reproduction in type IV dental stone dried at room temperature and in microware oven. J. Appl. Oral Sci., 2012, (22); 14.

11. Poobal Asignam S., Laksmanan N.. Optimum energy for peak performance with Scalar energy: (Fifth Edition) 2017.

12. Cair. R, Yang H., Zhu W.: The effect of magnetic fields on water molecular hydrogen bonds J. Mol. Struct. (938), 2009, 75-19.

13. Lipns L. C., Hamler A., Ban I., Ackor B.. Permanat magnets for water-Scale prevention J. Advanced in Production Engineering and Magenta Volum (1); No. 4., 2015, PP. 209-216.

14. Han X., Peng Y., Ma Z.: Effect of magnetic field on optical features of water interface Sci., (16) 127, 2016, 6321-6.

15. Anaraki MR., Moslechifand E., Bahari M., Mahboubi S.. Effect of repeated microware disinfection on 
surface handness and dimesion accuracy of two dental stone materials, advances in Bioscience and clinical Medicin J., Vol. Q3. No.. Q1; 2014: 2203-1413.

16. Anusavice KJ., Philips: Science of dental materials., $10^{\text {th }}$. Edition, philidelphia.1996, P. 62, 203.

17. Hossain. M, Sahmavan., M, Taug., E: Static magnetic field on tensile strength of dental stone: Material.int. J., (1049), 2016: 35.

18. Ounceal., Bilnschi L., Iones L Effect of disinfectant solution incorporated in dental stone on setting expansion, compression and flexional strength of dental models; (30), J. Ramanian Biotech; 2018, (30).

19. Sinesu. S, Goodavie. J, Hatoor. H., Chemical surface treatment at different dental material with magnetize water: Dental practice, J. (6); 2017, 531- 539.

20. Mohammed AA: Evaluation of some properties of gypsum products and acrylic resin by the use of some additives and microwave techniques Msc. Thesis, University of Mosul, 2006.

21. Donovan J., Jacob. RF., Anderson. GC: Dimension accuracy of Dental stone reacted with magnetized water: J; Prosthe. Dat; Geneone (112), 2017.

22. Sfarghlu L. C., Oancea L., Litesca $\mathrm{R}$ : The influence of disinfectants in corporation on die stone linear expension. Rom. Bio. J., (3), 2010, 21-11585-11590.

23. Wang Y. Wei A., Li Z.: Effect of magnetic field on the physical properties of water., results in physics J., 2018: (8) 262-267.

24. Ghorbani S., Gholizadeh M., Brito J.: Effect of magnetized water on the mechanical and durability properties of concrete block pavers. Md pi. J., 2018: (11) 6677.

25. Esmaeilnezhad E., Choi L., Schaffie M., Ranbar M.: Charactertic and application of magnetized water as a green technology j. clean. Prod:, (161). 2017: 908-927. 
26. Orlov E., Andranor A. The assessment of magnetic water Treatmant on the formation calcium scale on reverse osmosis member, J. Matec. Conference., 2018: (178) 090007. 